\title{
FIBRILLAR MATERIAL AS A COBINDER IN COATING COLORS FORMULATIONS
}

\author{
Dimić-Mišić Katarina* \\ Aalto University, Helsinki, Finland \\ Dr Paltakari Jouni \\ Aalto University, Helsinki, Finland
}

The micro-fibrillated cellulose (MFC) is a potential material which will at least partly substitute the synthetic co- binders, such as carboxymethyl cellulose (CMC), in paper coating color formulations. Co-binders play an important role in controlling both the flow properties and the dewatering rate of coating colors during the application process as well as during the subsequent film immobilization [25, 19, 02]. In this study, MFC fibers are used to substitute standard, synthetic co-binder material, CMC, affecting both dewatering and rheological properties of coating colors. This study was partly attempting to establish standard measurement procedures that can give overall picture of complex rheological behavior of MFC coating colors. Elastic effects of coating color in low shear rate influence both the flow and blade load [23]. By influencing leveling, elasticity, substitution of CMC with MFC influences coating color application and immobilization process, as well as the uniformity and optical properties of the coating film [06] . It has been demonstrated that coating colors which contained MFC fibers as a co-binder had pronounced shear-thinning characteristics which is a desirable property for paper coatings. However, a complete substitution of CMC with MFC fibers in paper coatings induced low retention properties, longer shearrecovery time and fast immobilization of coating colors, which can have a negative influence on leveling and final coating layer uniformity. Coating suspension rheology of the coating influences the coating performance at high speeds. The quality of the coated and printed papers is also affected by the rheology of the suspension [06,26]. Co-binders play an important role in controlling both the flow properties and the dewatering rate of coating colors during the application process as well as during the subsequent film immobilization $[23,06]$. The micro fibrillated cellulose (MFC) is a potential material which will at least partly substitute the synthetic co- binders, such as carboxymethyl cellulose (CMC), in paper coating color formulations [08,22]. It was expected that the introduction of the MFC material into the coating formulation affects the coating color rheology since the MFC fibers are highly flocculated and have reactive groups on their surface [08].Micro-fibrillated cellulose material (MFC), can beproduced through several pre-treatment and refining routes, each giving products with very differentmorphological and chemical properties [18].It is expected that refining and treatment route of MFC influence traditional coating layer properties as those designed for special purposes [18]. The observation that MFC could be used in paper coating formulations, as a co-binder, since it is biodegradable and has good shear thinning properties, raises a question about the processability of MFC coatings in a high speed coating process(above $1000 \mathrm{~m} / \mathrm{min}$ ) [12]. This work focuses on determining general rheological and dewatering behavior of coating colors that contain MFC fibers used as co-binders. A thickener is added to prevent an excessive loss of water from coating color into the base paper and to adjust the rheological properties of the color, a thickener is usually added [03,28]. The physical and chemical properties of the thickeners differ, and they can be roughly divided into synthetic and natural polymers [01]. Water retention and immobilization are the key properties for successful paper coating formulations [21,05]. The task of research is to evaluate how the replacement of CMC co-binder with MFC material influences the viscoelastic and dewatering properties of the coating color [07]. Correlation of the data matrix obtained from dewatering, low-shear viscoelastic and immobilization time measurements show that there is a pattern providing general understanding of the MFC fiber performance in coating suspensions. It is important to understand what the typical behavioral pattern of all MFC coatings would be once they are in the coating process. A key characteristic of the response of a viscoelastic material, as are coating colors, to its deformation during dynamic process, is its ability to recover after cessation of the force which causes deformation [13,04].

*Aalto University, PO Box 110000 Aalto, Finland; katarina.dimic.misic@aalto.fi

Paper presented at SIE 2012 
Pigment reactivity with binders and co binders has an important effect in viscoelastic behavior of coating color. It has been proved through many previous research papers that more elastic structures of clay coatings yield larger elastic moduli than the carbonate coatings [05,14].

Key words: Property, Fiber, Coloration, Coatings, CMC

\section{OBJECTIVES}

As micro-fibrillated materials are known to be highly flocculated gel emulsions, it was necessary to examine what kind of reactivity they have with coating pigments and other chemicals in coating formulations. The possible differences in this reactivity with respect to the fiber fineness, and pigments types were also to be determined. In order to get a deeper understanding of MFC fibers used as co-binders and such coating colors rheology, this study aim to give in-depth investigation of the rheological behavior of such coatings in shear rates of industrial interest. Reference, standardly used coating formulations having co-binder CMC, were rheologically and in dewatering terms compared with the MFC-containing coatings. Two different pigments were used, and coating colors made from carbonate, kaolin, and $50 \%$ mixture of kaolin and carbonate. Reactivity of differently charged kaolin(anioniccationic)) and calcium carbonate (all sides cationic) with MFC fibers is expected to increase viscoelasticity though interaction with highly reactive hydroxyl groups of MFC fibers and charges on particles. Bridging mechanismis expected to link MFC fibers and pigments together. After data analysiscorrelationfactorswere calculated between the coating color recipe properties (i.e. solid content, relative amount of nano-fibers per amount of pigment) and coating performance responses. Static dewatering, viscoelastic and low-shear oscillation rheological measurements were accompanied with an immobilization cell, which uses dynamic dewatering data to measure final immobilization time of the coating layer $[09,11]$. These measuring techniques make connection between the microscopic state of coating suspensions and their macroscopic behavior in process flows.

\section{EXPERIMENTAL MATERIALS}

\section{MFC fibers specification}

Micro fibrillated cellulose was obtained from UPM -Kymmene Corporation. It was prepared from never dried birch pulp by different pretreatment and refining methods. Masuko was prepared as pulp was passed once through a Voith refiner (Voith AG, Germany) and then seven times through Fluidizer M7115 (microfluidics corp.)The first pass was through a chamber with diameter of $500 \mu \mathrm{m}$ and $200 \mu \mathrm{m}$ and the rest through chambers with diameters of 500 and $100 \mu \mathrm{m}$ at a pressure 1,850 bar.The final solid content of suspension was $3 \mathrm{wt} \%$, and the fibers contained about $25 \mathrm{wt} \%$ xylene. Tempo mediated cellulose was obtained as well from UPM -KymmeneCorporation. It was prepared using tempo-mediated oxidation of native cellulose followed by disintegration of the oxidized cellulose fibers in water using a Warning blender.Transmission electron microscope (TEM)observation of the dispersions showed that mostly individualized cellulose fibrils 3-5 $\mathrm{nm}$ in width were obtained, Table 1. Swelling and dispersion behavior of the cellulose in water were studied in detail in terms of carboxylate content by spectroscopic microscopic and viscosity analysis, data property of UPM -Kymmene.

\section{Pigments specification}

Two types of pigments were used for both reference (CMC-binder) and MFC coating colors, Tab.1.Coating colors with different pigment packing abilities (Capim RO kaolin and two different carbonate pigments $\mathrm{HC}-60$ and $\mathrm{HC}-90$ ) were compared in relation to different co-binders.

Table 1: Pigments specification

\begin{tabular}{|c|l|}
\hline$T_{t}$ & $\begin{array}{l}\text { Tempo- mediated with } 2 \% \text { pretreatment } \\
\text { chemicals }\end{array}$ \\
\hline$T_{f}$ & $\begin{array}{l}\text { Tempo-mediated with 4\% pretreatment } \\
\text { chemical }\end{array}$ \\
\hline$M_{f}$ & $\begin{array}{l}\text { Masuko treated, 15\% carboxymethylated } \\
\text { pretreatment I }\end{array}$ \\
\hline \hline$T_{e}$ & $\begin{array}{l}\text { Tempo-mediated ethanol- dried with } \\
\text { pretreatment chemical }\end{array}$ \\
\hline$T_{d}$ & Tempo-mediated, dried \\
\hline$C_{m d}$ & $\begin{array}{l}\text { Masuko treaded, carboxymethylated } \\
\text { pretreatment and drying prior refining }\end{array}$ \\
\hline$T_{f s}$ & $\begin{array}{l}\text { Tempo-mediated, carboxymethilated and } \\
\text { dried }\end{array}$ \\
\hline$C_{m e}$ & $\begin{array}{l}\text { Masuko treaded, carboxymethilated prior } \\
\text { to refining }\end{array}$ \\
\hline
\end{tabular}


Pigments were obtained as pigment slurries in cases, carbonate $\mathrm{HC}-60$, of $35 \%$ consistency and $\mathrm{HC}-9037 \%$ consistency (HC-60 /HC-90 with $60 \% / 90 \%$ less $2 \mu \mathrm{m}$ particle size). Kaolin Capim RO was obtained as slurry, $35 \%$ consistency.

\section{Water retention value WRV}

The wet Tempo-mediated cellulose (Td) and MFC (Mf) were centrifuged at 4500 gravity for 20 min in mixture with reference birch pulp, with different relative consistency, Figure. 1

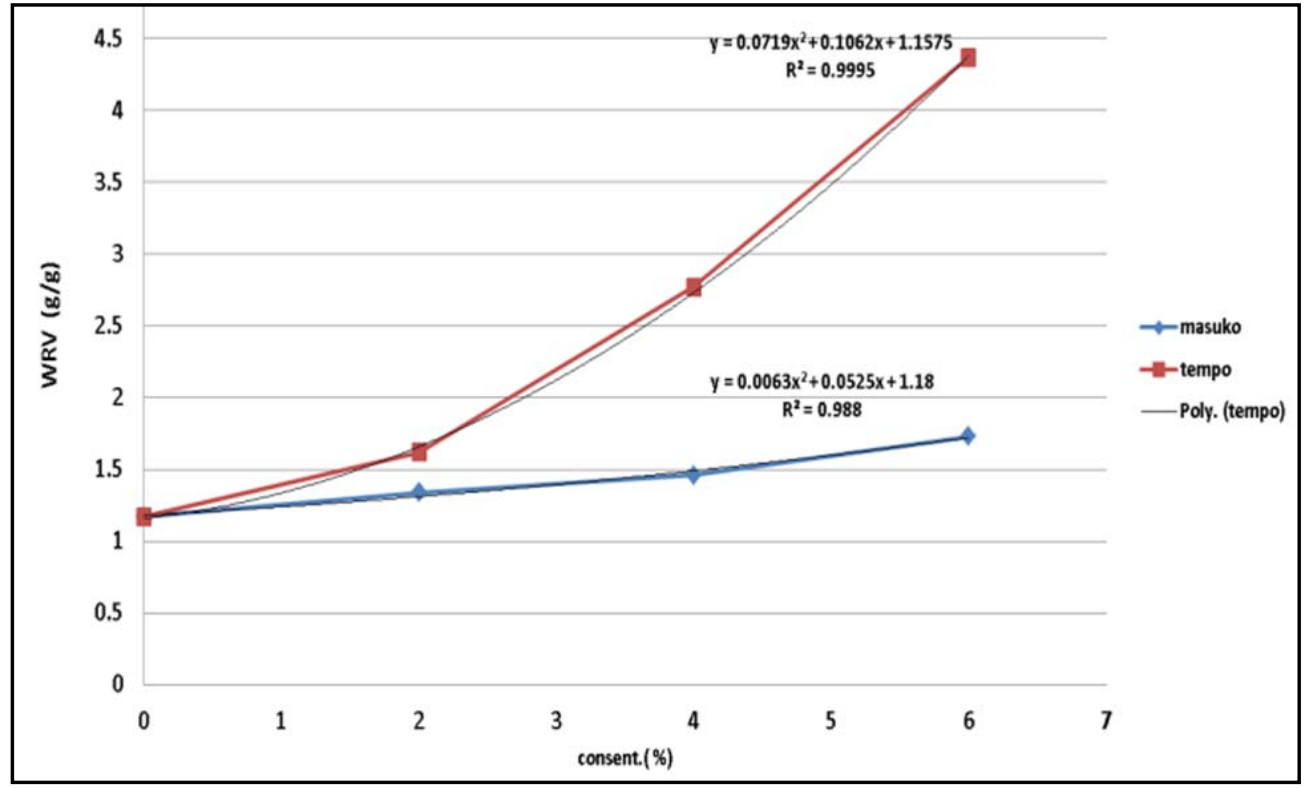

Figure 1: Apparent WRV for MFc fibers

Relative water retention value calculated by interpolation method is presented in Table 2. It is obvious that water retention value for tempo fibers is much higher as generally this fibers are having more reactive groups on fiber surface and have more swollen cell wall. It is more difficult for water to flow through such highly swollen fibers network and go through easily sealed opening of filter cake.

Rheological measurements Viscoelastic properties of the suspensions were measured with a stress controlled MCR 300 PaarPhysicaRheometer rotational rheometer, plate-plate geometry with anPeltier element temperature control, temperature during measurements was $23^{\circ} \mathrm{C}$. The gap between plates was $1 \mathrm{~mm}$.

Table 2: Relative water retention value calculated by interpolation method

\begin{tabular}{|l|c|c|}
\hline & $\begin{array}{c}\text { consistency of MFC } \\
\text { fibers in filter cake } \\
\text { suspention w/w \% }\end{array}$ & $\begin{array}{c}\text { WRV, g } \\
\text { water/g } \\
\text { dry fiber }\end{array}$ \\
\hline Masuko 3 & 2 & 9,68 \\
\hline Tempo UPM & 2 & 24,024 \\
\hline
\end{tabular}

Apparent yield stress were determined using amplitude sweep of $1 \mathrm{~Hz}$ frequency and strain of
0,01-100\%). Critical strain of MFC fibers suspensions was determined for consistency of fibers $(1,1.5,2$ and $2.3 \%)$ as a point of the breakage of structure in fiber suspension, and can be calculated as $\mathrm{T}=\mathrm{G}^{0} \mathrm{C}$, were $\mathrm{G}^{0}$ is storage modulus for liner viscoelastic region, Figure 2.

Masuko fibers have higher yield stress as they have less reactive fiber surfaces, less swollen fiber walls and there is more friction between fibers during shearing, which shows as higher storage moduli.

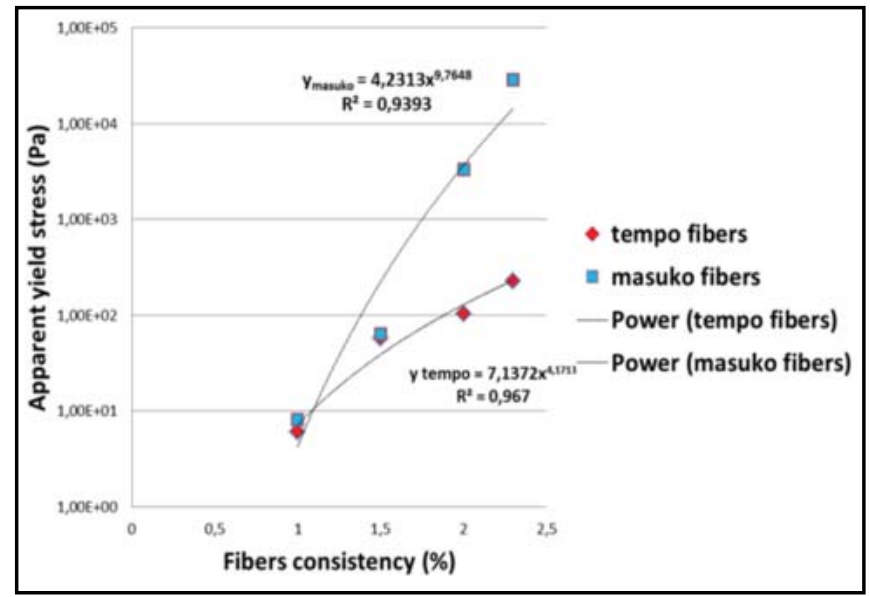

Figure 2: Apparent yield stress of MFC fibers 


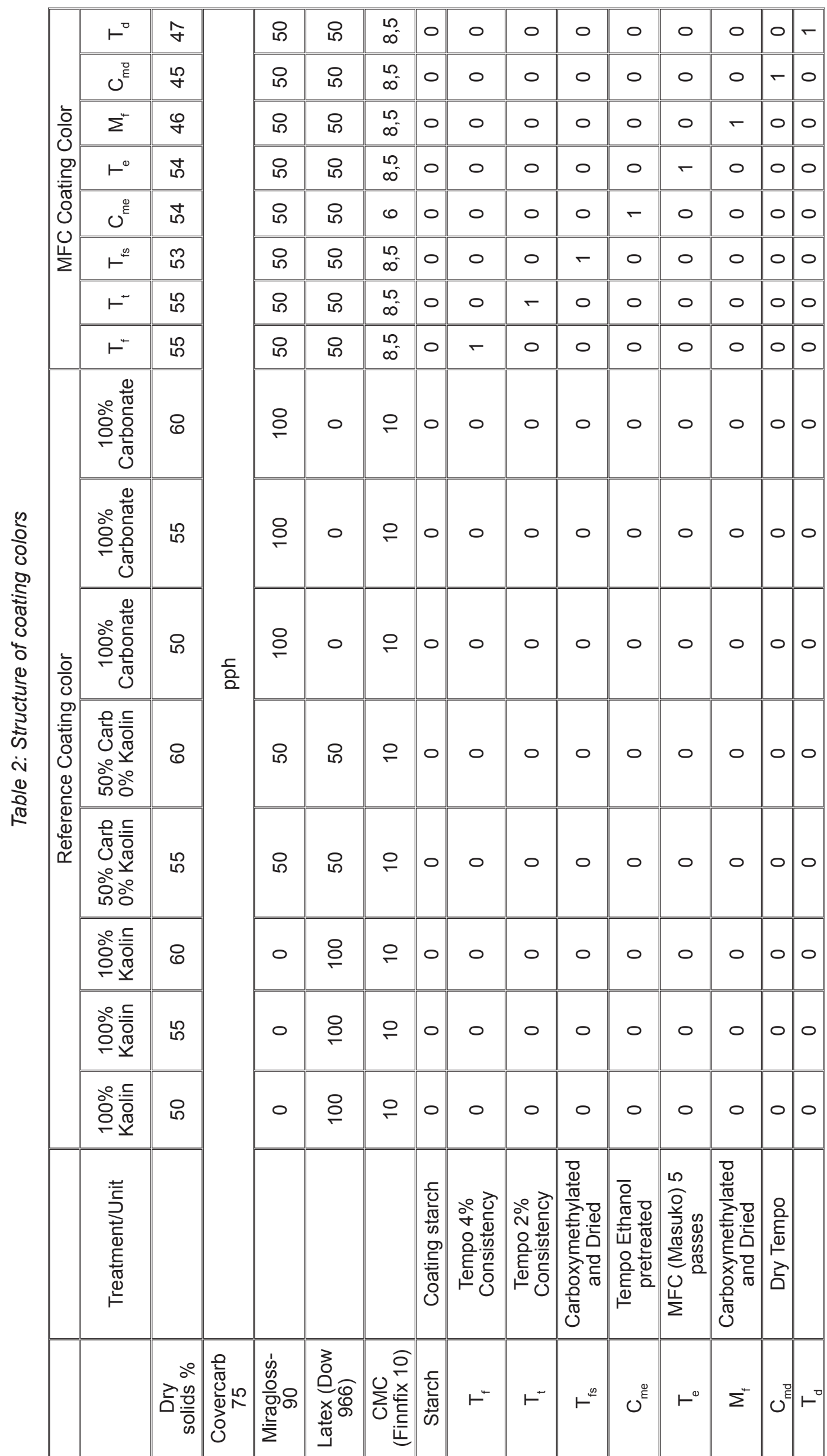




\section{COATING COLORS}

Reference coating colors were made in thjree different solid content $(50,55$ and $60 \%)$ and pigment types (kaolin, carbonate, blend of $50 \%$ kaolin and $50 \%$ carbonate), Table.2. Carboxymethyl cellulose $(\mathrm{CMC})$ was chosen as water soluble thickener in the reference coating colors, making the suspensions susceptible to depletion flocculation. In addition, the $\mathrm{pH}$ of each coating material mixture was adjusted to approximately 9.5 using $\mathrm{NaOH}$. For MFC coating color preparation for thickener was used Finnfix-10, purified low viscous carboxymethyl cellulose, with degree of substitution of $0.60-0.95$, and FF-10 is usually used in coating colors as thickener. MFC coatings were made with blend of $50 \%$ kaolin and $50 \%$ carbonate pigments.

Solid content of MFC coatings was adjusted, so that their Brookfiled100 viscosity stayed within coating color viscosity window, recommended for coating colors, 3000 Pas. Coating colors were prepared following the next order; pigments, OBA, NFC /CMC, with half an hour mixing and then Latex.

Testing of the coating colors was first done according to quick test procedure, dry solid content oven drying, Brookfield viscosity 50 and 100 RPM and ÅA-GWR(ÅboAkademi Gravimetric Water Retention Device). Additional dynamical low-shear measurements were performed on a MCR 300 PaarPhysicaRheometer, plate-plate geometry, gap $1 \mathrm{~mm}$. The immobilization cell accompanied on rheometer IMC enables the recording of the time to immobilization, i.e. the time for complete build-up of filter cake. The immobilization cell enables monitoring of the dewatering process of applied layers and controlled shear forces through increase in elastic moduli $G^{\prime}$ and $G$ " of suspension $[14,09]$.

\section{RESULTS}

\section{Reference coating colors-carboxymethilated cellulose as co-binder}

As can be seen from Figure 3, the gravimetric dewatering of reference coating colors increases in the order: kaolin< $<\mathrm{CaCO} 3$, and at the same time decreases with increase in solid content. This is due to the shape and electric charge of carbonate and kaolin pigments [06, 26, 14], as water passes easily through carbonate pigments but platy kaolin pigments make this passage more difficult.

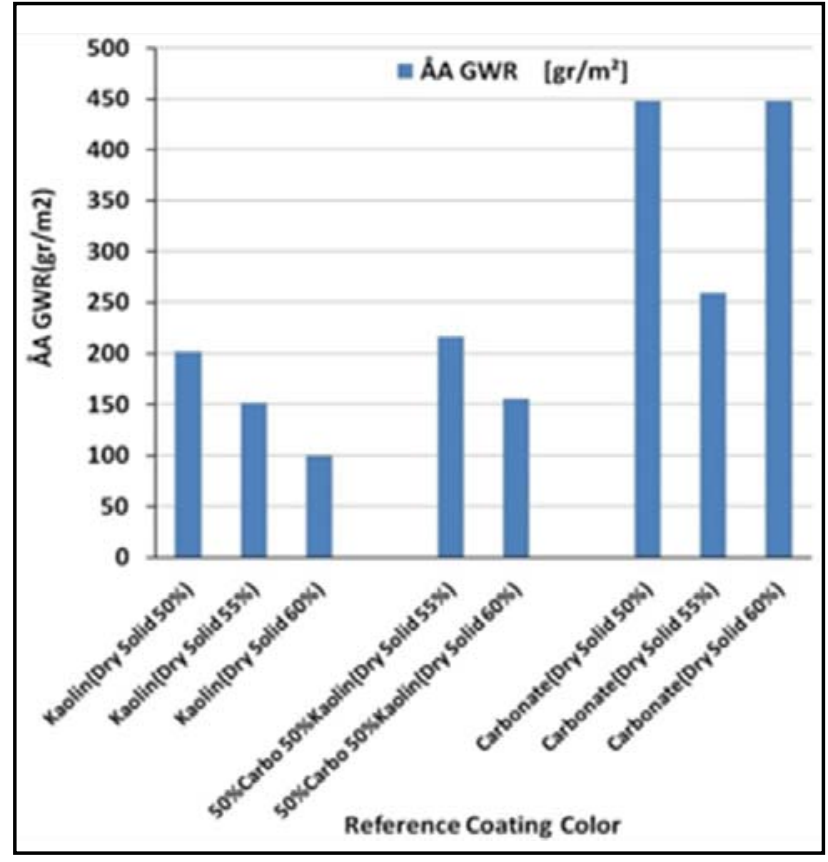

Figure 3: Gravimetric dewatering of reference coating colors

It is obvious that kaolin pigment coating color has a more pronounced shear thinning behavior as kaolin with CMC forms three dimensional structure in a coating dispersion ("house of cards" structure) which brakes when shear is applied, only to be again reconstructed after shear ceases [24].Decrease in apparent viscosity measured with increase in spindle rotation rate, from 50 to 100 RPM is shown in Figure 2.

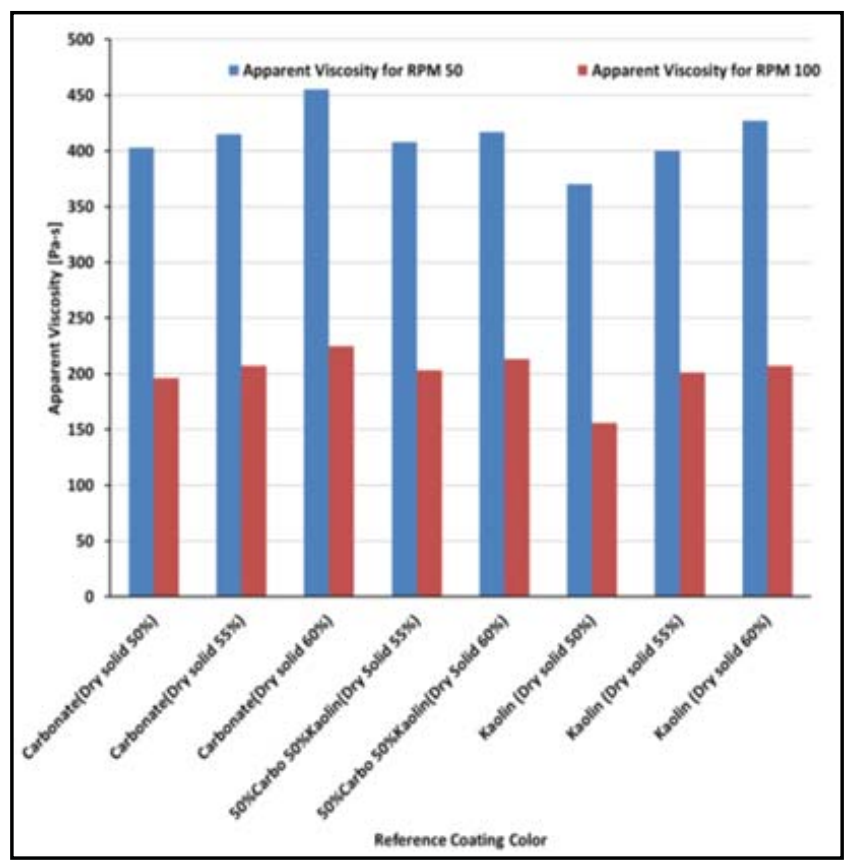

Figure 4: Brookfield viscosity of the reference coating colors 
When measured apparent viscosity on Brookfield viscometer, it is obvious that kaolin pigment coating color has a more pronounced shear thinning behavior as kaolin,through molecular bridging with long $\mathrm{CMC}$ chains forms three dimensional structure in a coating dispersion ("house of cards" structure) which brakes when shear is applied, only to be again reconstructed after shear ceases [11, 24]. Decrease in apparent viscosity measured with increase in spindle rotation rate, from 50 to 100 RPM is shown in Figure 4. Within the frequency sweep test $(0,01-100 \mathrm{~Hz})$ within the linear viscoelastic region ( $1 \%$ strain), elastic modulus of clays is higher than that for carbonate coatings, Figure 5.

Particle flocks induced by hydrodynamic and surface interactions group together into a macro scale three-dimensional network which comprises the elastic structure of the coating dispersions [20]. Same figure shows that elasticity expressed as storage modulus $\mathrm{G}^{\prime}$, is higher for kaolin based than carbonate-based coating colors, for all three consistencies, and elasticity is increasing with solid content with more dense packaging of material.

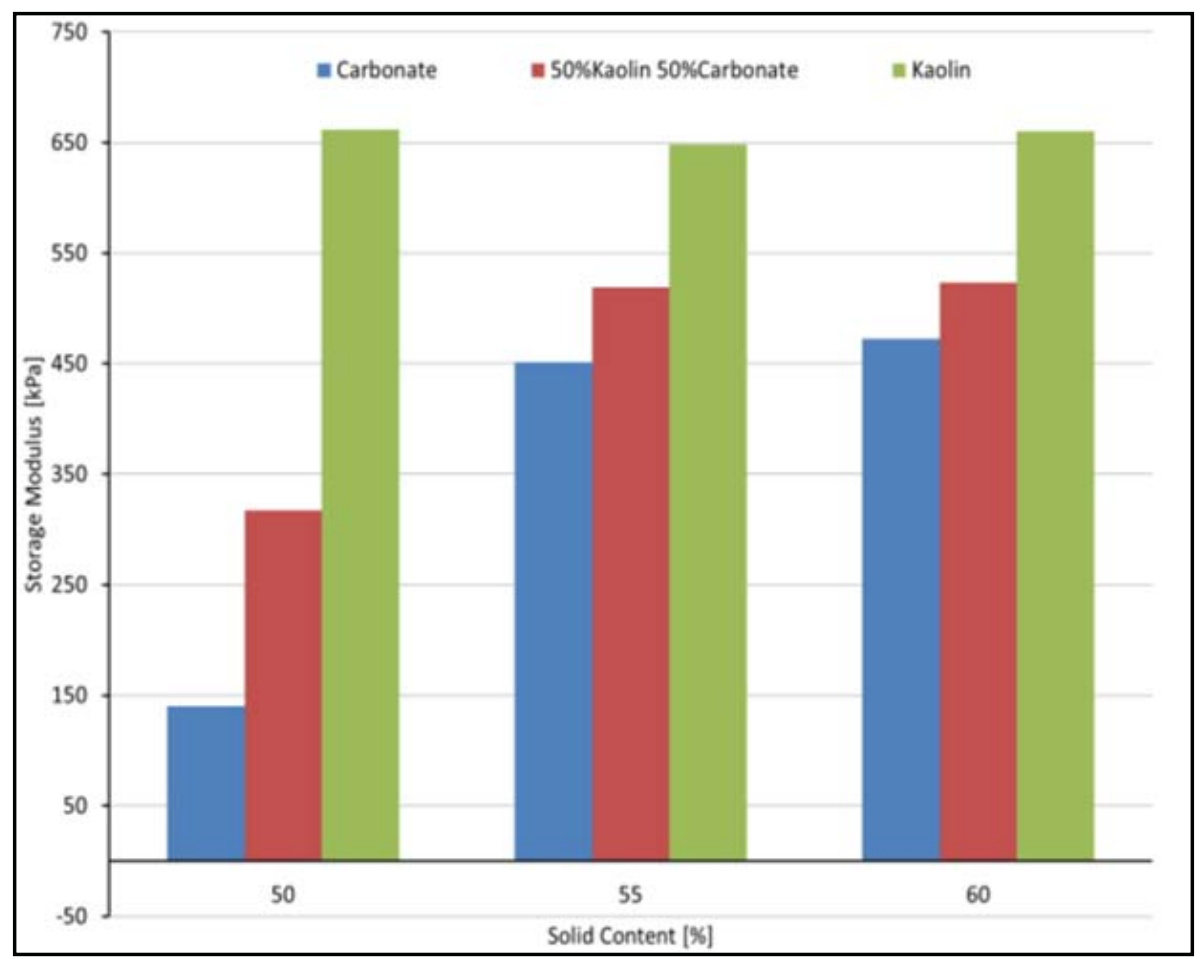

Figure 5.a

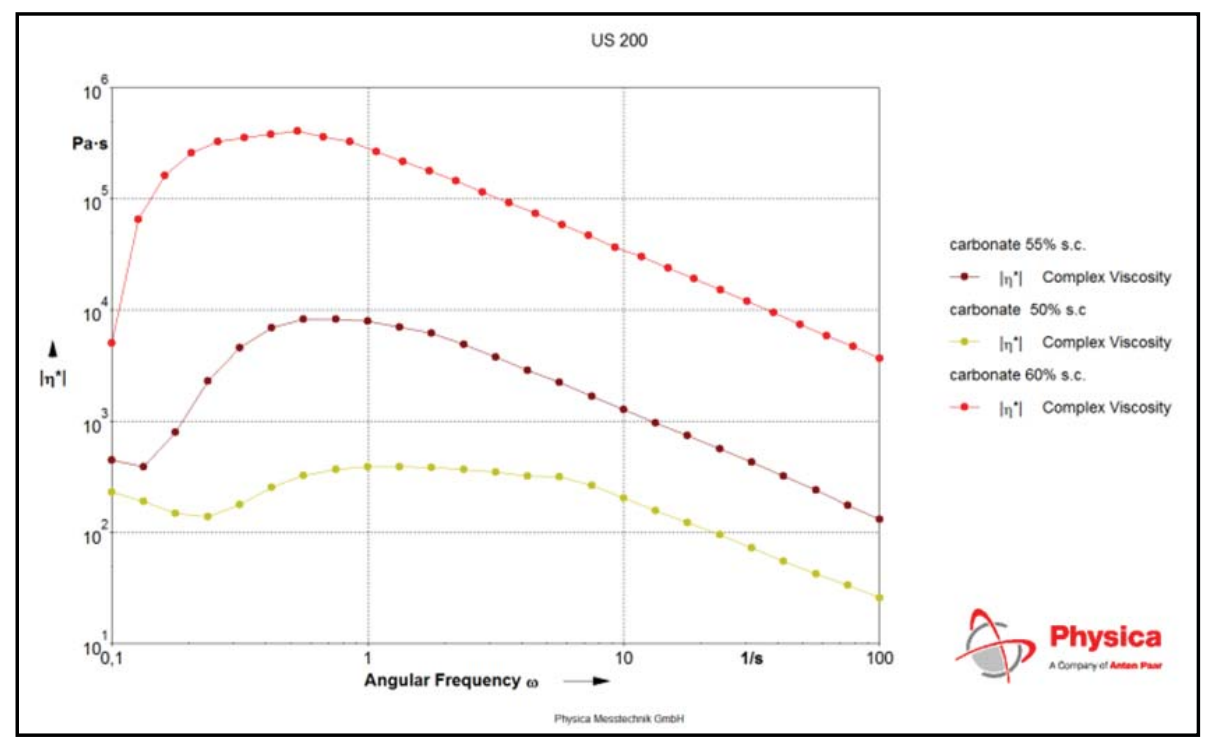

Figure 5.b 


\section{MFC coating colors-micro fibrillated cellulose material (masuko and Tempo based) as a co-binder}

As a reference coating for this evaluations was used blend of $50 \%$ kaolin $50 \%$ carbonate coating color, with $55 \%$ consistency, and dewatering band rheological behavior of this particular reference coating color was compared with behavior of MFC coatings.

Since MFC fibers have very high water retention as presented at Figure 2, the gravimetric dewatering of MFC based coating colors show higher retention values than for reference coatings, Figure 6. Pretreatment and production route of MFC fibers has as a product fibers with different swelling of fiber wall and surface reactivity and thus some fibers as Mf and Td induced as co-binders drastically increase water retention, while some decrease, as with sample $T_{e}$.

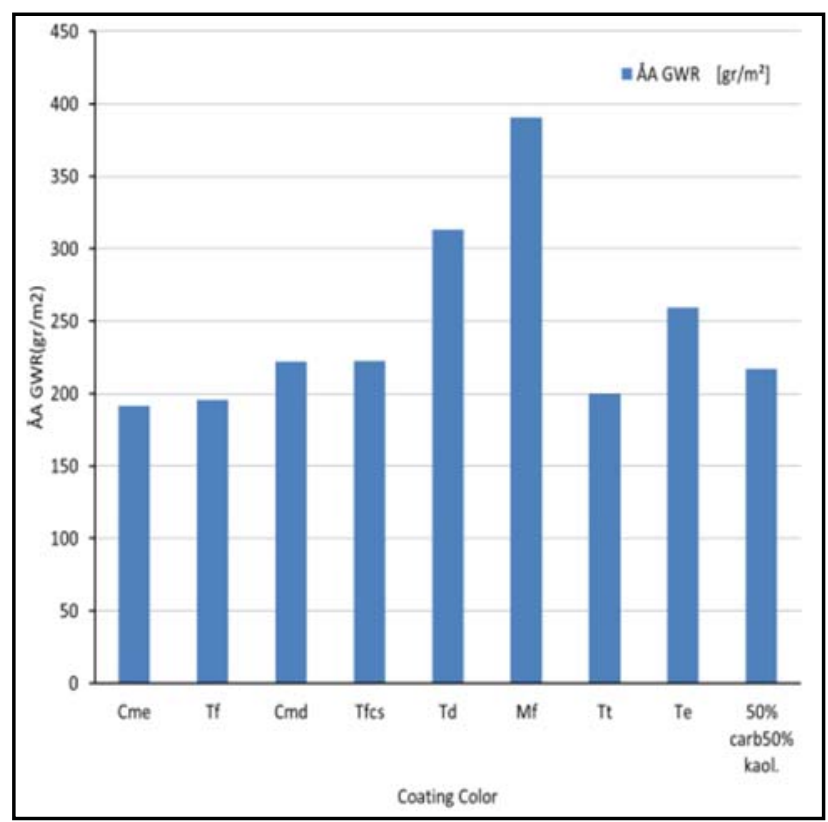

Figure 6. AA-GWR Water retention values for MFC coating colors

For some MFC coatings $\left(T_{f}, T_{t}, C_{m e}\right)$ apparent (Brookfield viscosity at 50 and 100 RPM) is much higher for MFC coatings than for reference one, as a product of reactivity between pigment particles and highly reactive MFC fibers, while for others $\left(M_{f}, T_{d}, T_{\text {fcs }}\right.$ viscosity is lower, Figure 5.a and 5.b. It is important that the coating color immobilizes quickly after metering, and therefore too long immobilization times are not desirable $[17,16]$. High solid content normally means a faster immobilization of the coating layer, which reduces the structural changes of the paper ma- trix under the coating layer, but in the case of MFC faster immobilization is achieved with lower solids than in conventional coatings.

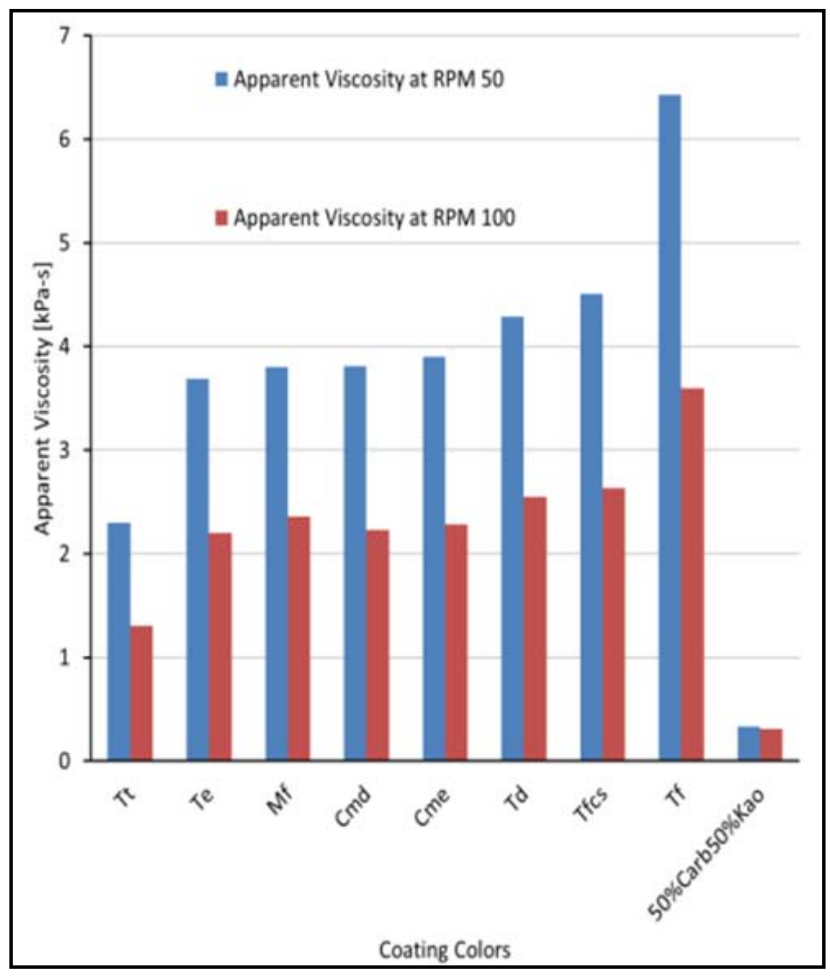

Figure 7: Brookfield viscosities for MFC coating colors

Flow behavior of coatings prior to metering and after the exit from the blade nip depend, to a certain extent, on the viscoelastic parameters, as viscoelasticity influences consolidation on the wet coatings [11, 27]. Wet paper coatings demonstrate a fading memory of recent shearing. The magnitude and rate of recovery after application are defined by the formulation and process speed [13].

Rheological measurements done in frequency sweep mode $(0,01-100 \mathrm{~Hz})$ at temperature $23^{\circ} \mathrm{C}$ on MCR 300 rheometer show complex viscosity development for coating colors when samples go from low to high shear, in linear viscoelastic region. The double logarithmic plot in Figure 8 depicts the power law shear thinning behavior of the complex viscosity of MFC coatings, typical for a gel like structures.

For some MFC coatings $\left(T_{f}, T_{t}, C_{m e}\right)$ maximal complex viscosity is much higher than for reference coating, while for others $\left(M_{f}, T_{d}, T_{f c s}\right)$ maximal complex viscosity is lower, Figure 8 . Ratio of maximum and minimum complex viscosity within a defined frequency sweep was calculated and is presented in Figure 9. Shear thinning behavior, desirable in coating process is obtained when MFC fibers are replacing traditional $\mathrm{CMC}$ co-binder. 


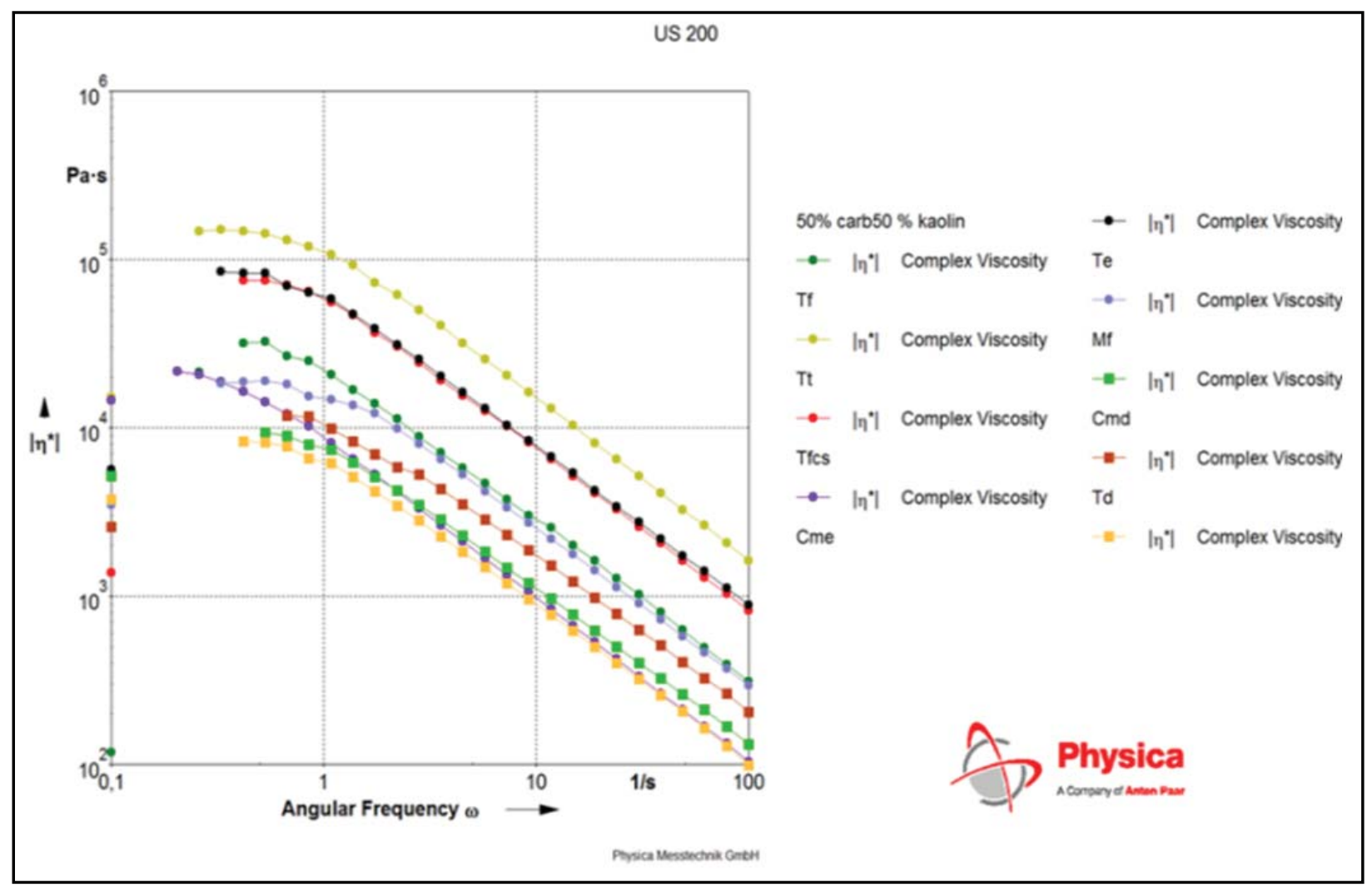

Figure 8. Complex viscosity curves for NFC and reference (50\%. kaolin and $50 \%$ carbonate) coating colors; frequency sweep

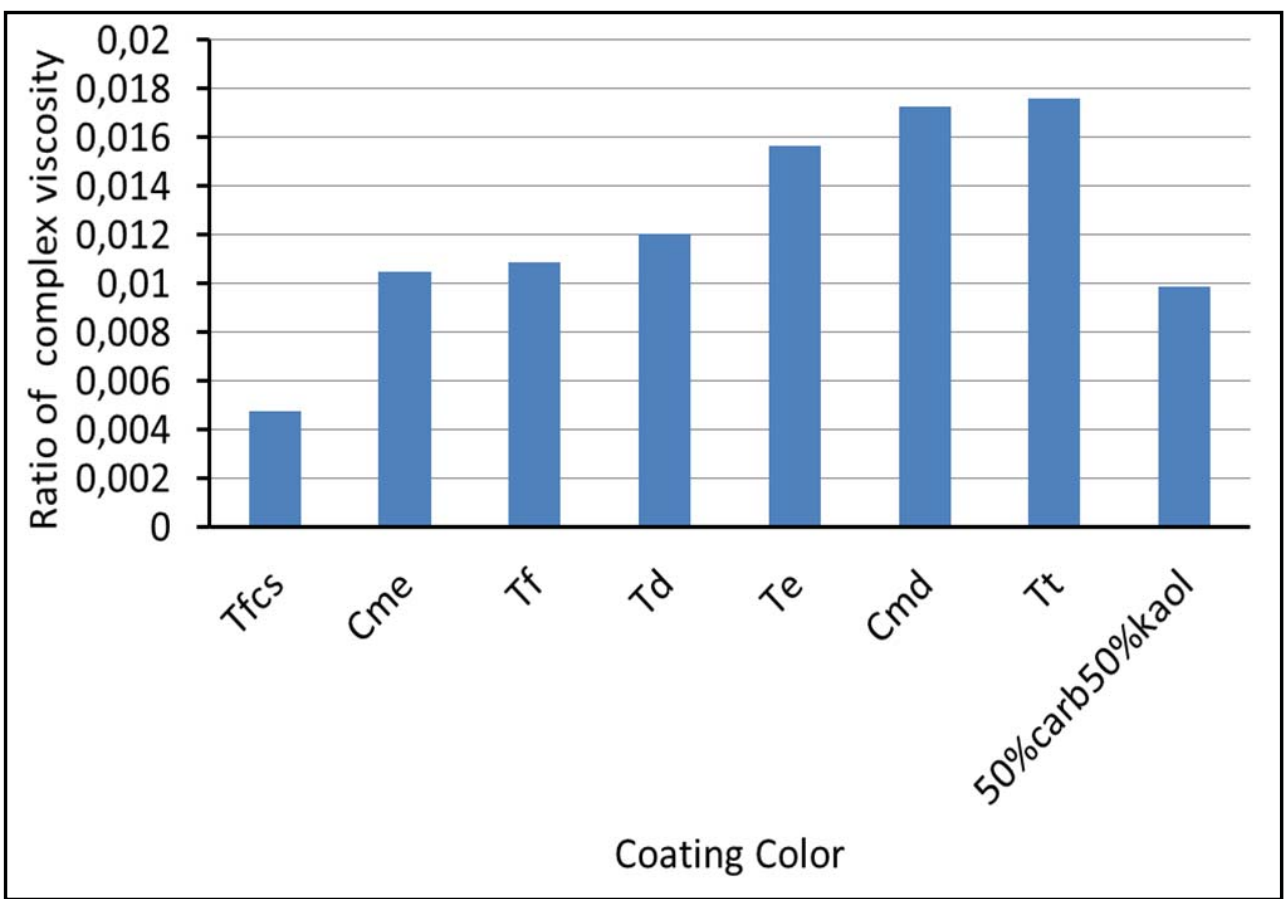

Figure 9: Shear thinning, ratio of Max/Min complex viscosity for MFC coating colors within a frequency sweep of $0.1-100 \mathrm{~s}^{-1}$

During frequency sweep measurements MFC coatings have much higher increase on elastic moduli $G^{\prime}$ at the beginning of measurement, at even very low frequencies, which is because of their high elasticity, which causes immediate response of coating colors to deformation, as Weissenberg effect as shown in Figure10. 


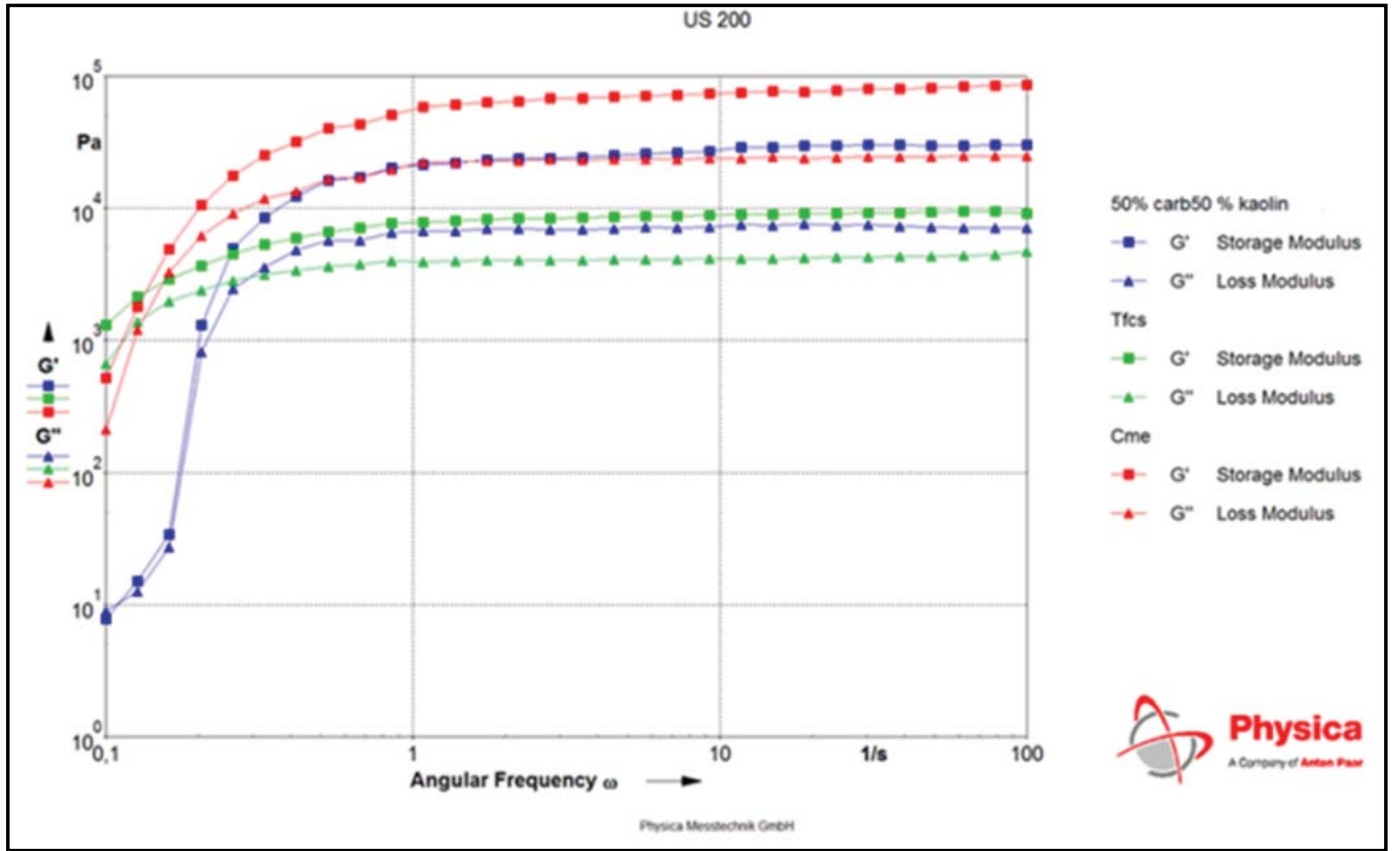

Figure 10: Amplitude sweep, storage and loss moduli- two different MFC coatings(Tfcs and Cme), compared with reference coating ( $50 \%$ carbonate $50 \%$ kaolin, solid content $55 \%$ )

It is important that the coating color immobilizes quickly after metering, and therefore too long immobilization times are not desirable [13]. Inter- estingly, MFC coating colors immobilize faster although they have a lower solid content than the reference CMC coatings, Figure 11.

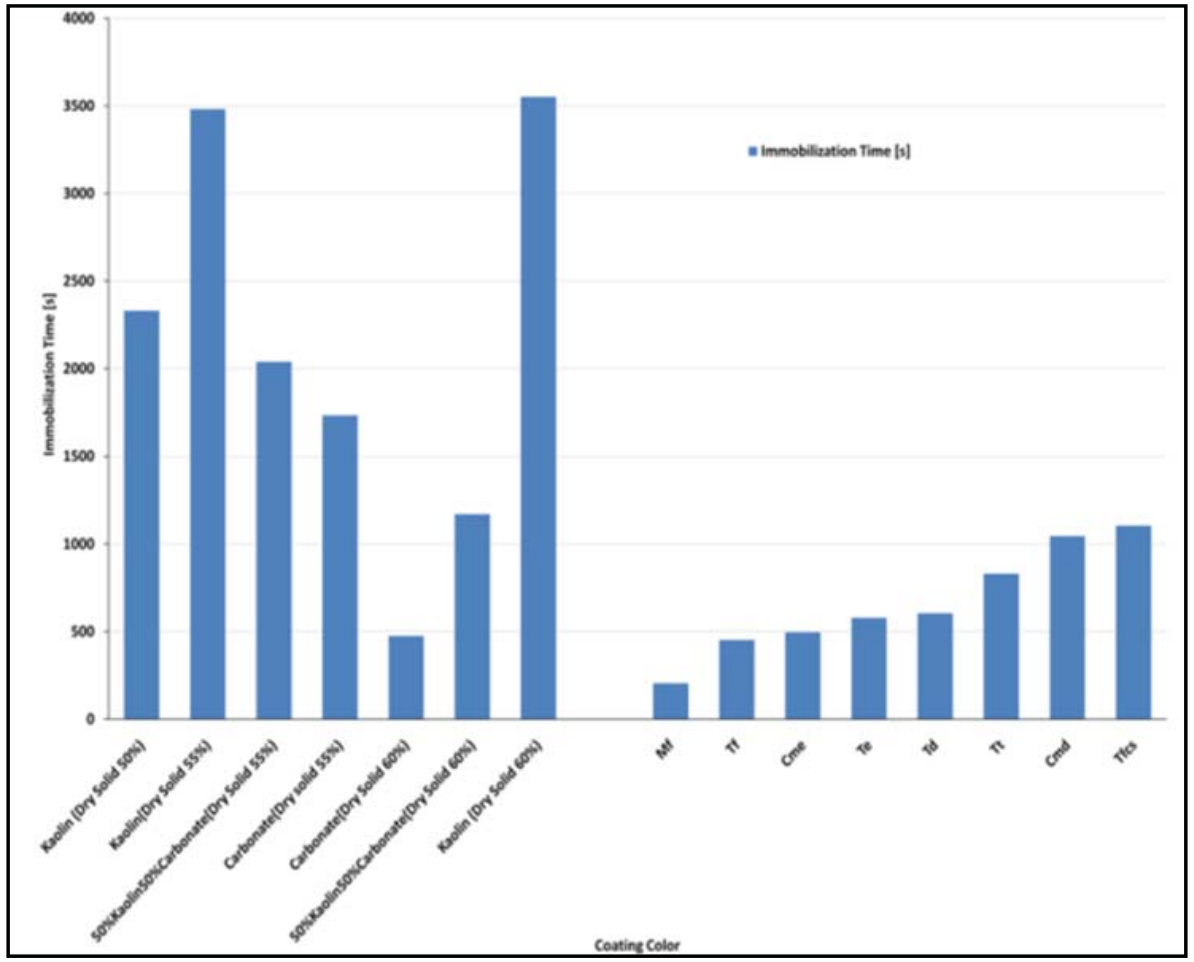

Figure 11: Immobilization time for MFC coating colors

A correlation matrix was made comprising data from static, AAGWR and dynamical low-shear dewatering with IMC results. Data obtained from these two measurements show a strong cor- relation, proving the hypothesis that those two measurements correlate [14, 09] as presented in Figure 12. 


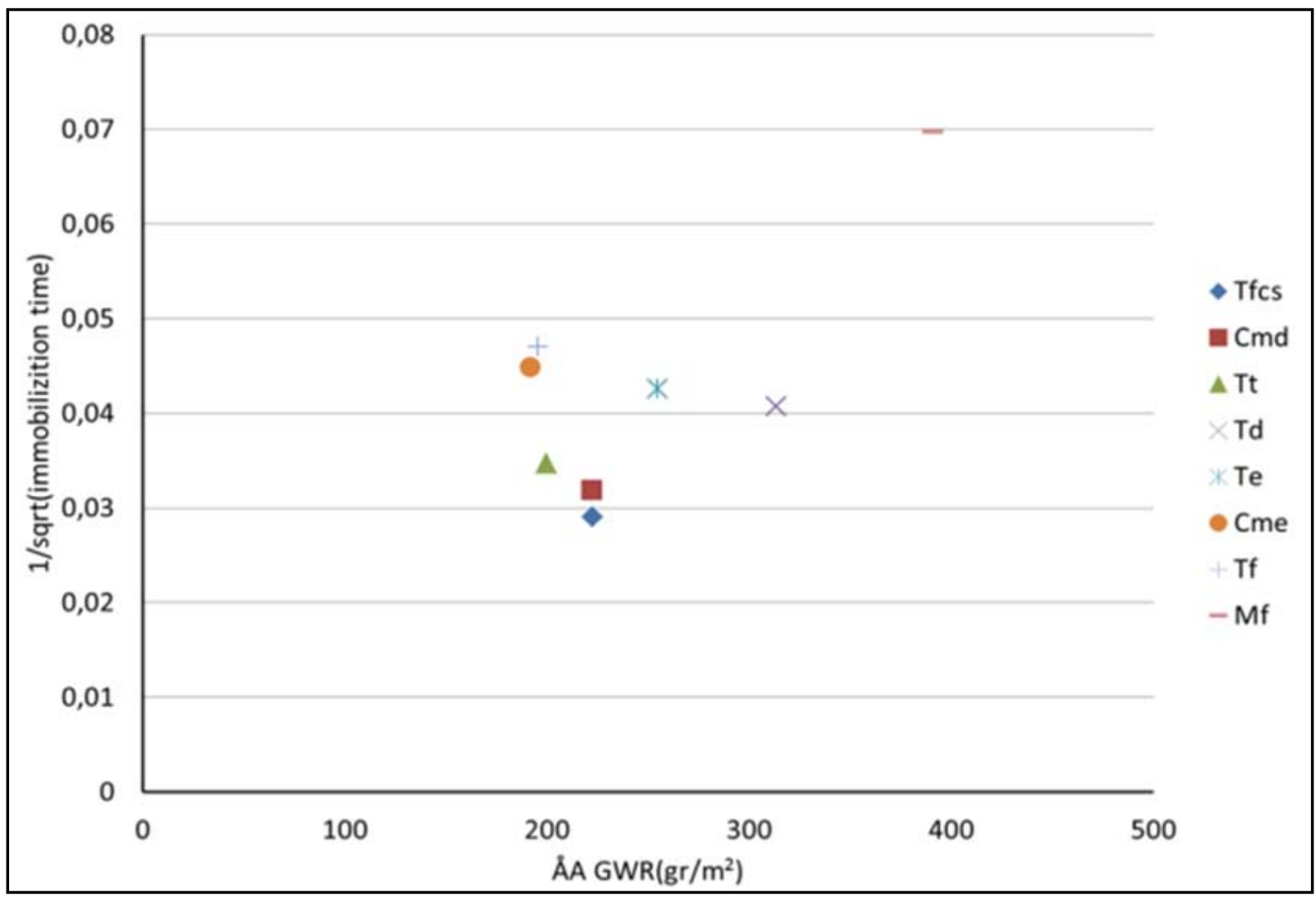

Figure 12: Correlation diagram AAGWR vs. Immo time, MFC coatings

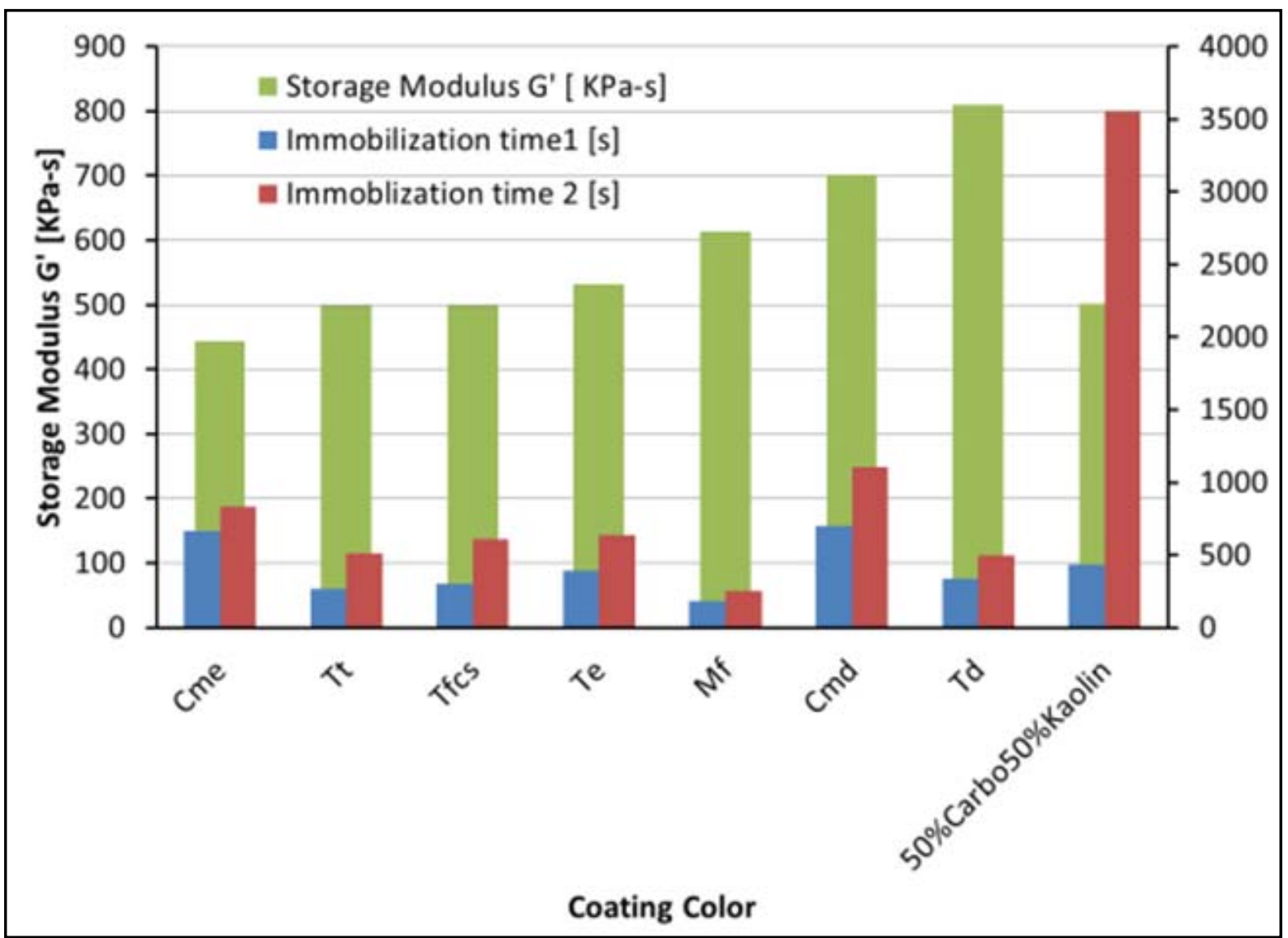

Figure 13: First and Second Immobilization time vs. final Storage modulus; MFC coatings 
High solid content normally means a faster immobilization of the coating layer [13], which reduces the structural changes of the paper matrix under the coating layer, but in the case of MFC faster immobilization is achieved with lower solids than in conventional coatings. Even though faster immobilization is desirable in drying process, high elasticity of MFC coatings filter cake can cause problems at leveling and metering nip. In several types of coating units, a more extended dwell time between application and metering leads to the formation of an immobilized coating color prior to leveling. It is evident from Figure 13 and 14 that for some types of MFC fibers, like for those carboxymethylated prior to refining $\left(\mathrm{C}_{\mathrm{md}}, \mathrm{C}_{\mathrm{me}}\right)$, both immobilization time and storage modulus of immobilized layer cake are in better range, more similar to those of reference coating colors.

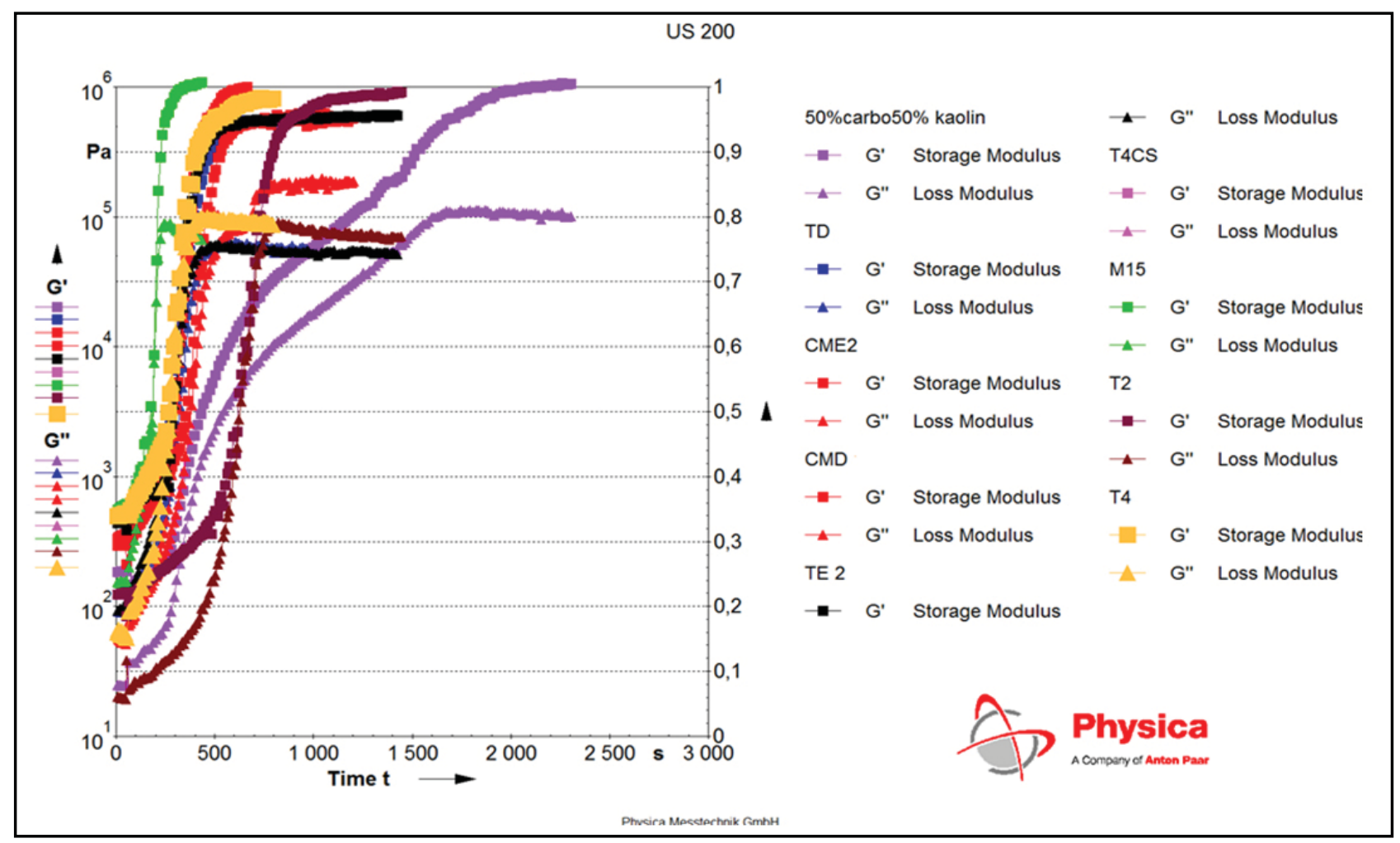

Figure 14: Immobilization diagrams; MFC coatings vs. 50\% carbonate $50 \%$ kaolin reference coating color

\section{CONCLUSION}

At low frequencies, elasticity of carbonate coatings increases with replacement of CMC with MFC fibers, while shear thinning is higher for MFC coatings which have kaolin inside. Lowshear frequency sweep oscillation measurements showed that MFC coating colors have astronger" memory effect" after shear from standard CMC coatings, as having higher elastic modulus. Results show that fiber finesse, hence pre-treatment and refining route of MFC fibers determines consolidation, low shear rheology and immobilization time of coating color, as well as there is different reactivity of fibers in respect to pigment types. MFC samples had different amount of fibrous material depending on the type of pretreatments, with less fibrous material indicating a better refining result, higher shear thinning effect, better dewatering /higher immobilization time with lower filter cake elasticity. Generally all MFC coatings had lower water retention and much faster immobilization, than reference $\mathrm{CMC}$ coating colors.

\section{Acknowledgement}

This data is from Author's Licentiate thesis "Influence of fibrillar cellulose on pigment coating formulation's rheology", supervising professor PaltakariJouni, published at Aalto University, Helsinki, 2012.

\section{REFERENCES}

1) Adams P. D andKuszewskiJ., Crystallography and NMR system: a new software suite for macromolecular structure determination, ActaCrystallogr, 1988, p. 18

2) Åkerholm J., Berg C. and Kirstilä V., An experimental evaluation of the governing mois- 
ture movement phenomena in the paper coating process, Part II, ÅboAkademi University, Finland

3) BackfolkK., Methods for controlling surface contact area of a paper or board structure, Doctoral Thesis, ÅBO Academy, Finland, 2002

4) BarnessH. A., Hutton J. F., WaltersK., An Introduction to Rheology, Coating Conference proceedings, Amsterdam, 1998

5) BourneP. andWeissigH., Structural bioinformatics A John Wiley \& Sons Publication, Figures. 15, 18, 34, 2003

6) BruunS-E., Pigment Coating and Surface sizing of Paper, Totally updated version, Paltakari J. ed., Ch. 14, PaperijaPuuOy, Finland, 2009

7) BruunS-E., Pigment Coating and Surface sizing of Paper, Totally updated version, Paltakari J. ed., Ch. 6, PaperijaPuuOy, Finland, 2009

8) Dreiffenbergl., Lohmander S., Effects of the air content on the rheological properties of coating colors, Advanced Coating Fundamentals Symposium, 1999

9) Eklund D, Grankvist T., Salahetdin R., Theinfluence of viscosity and water retention on blade forces, PTS Coating Symposium, 21stpaper, Munich, Germany

10) EngströmD. and Ridahl, On the transition from linear to non-linear viscoelastic behavior of CMC /Latex coating colors, Nordic Pulp Paper, 1991

11) EngströmD. and Ridahl, The effect of some polymer dispersions on the rheological properties of coating colors, Tappi press, 1989

12) GrovesR., Ruggles C., Paper Coating Structure - The Role of Latex, PITACoating Conference Proceedings, 1993

13) Jäder J. and JärnströmL., Calculation of filter cake thickness under conditions of dewatering under shear, Annual transactions of the Nordic Rheological Society, vol. 9, p. 113-117, 2001

14) Jäder J., Engström G, and Järnström L., Extensional Viscosity of paper coating Suspensions studies by converging Channel-flow and filament stretching, Annual transactions of the Nordic Rheology Society, vol. 12, 2004
15) JäderJ., Consolidation and Rheology at High Solid Content, Dissertation; Karlstad University Studies, 2004

16) Kugge $C .$, Consolidation and structure of paper coating and fiber systems, Doctoral dissertation, Stockholm, 2003

17) Kugge C., DaicicJ. and Furo, Compressional rheology of model paper coatings, fundamental research paper symposium, Pira international, Oxford, 2001

18) Leino M., VeikkolaT., A New Board Coating Method, TappiCoating Conference Proceedings, 1998

19) Lepoutre P., Coating structure and surface coverage, Symposium on Surface Coverage, Helsinki, Finland, 1999

20) Lepoutre P., Substrate Absorbency and Coating StructureTappi Journal, 61[5], 1978

21) Li J., Tanguy P., Carreau J., Moan M., Effect of thickener structure on paper-coating color properties, Colloid Polymer Sci. 2001

22) Paltakari J., Puu-21. 3060 Pigment Coating Technology, Aalto University, Finland

23) Pigment Coating and Surface sizing of $\mathrm{Pa}$ per, Totally updated version, Paltakari J. ed., Ch. 5, PaperijaPuuOy, Finland, 2009

24) Triantafillopoulos N., Paper coating Viscoelasticity, Tappi press, 1996

25) Watanabe J. andLepoutre P., A Mechanism for the Consolidation of the Structure of Claylatex Coatings Appl. Polym. Sci., 1982

26) Willenbacher N., Wagner H., High Shear Rheology of Paper Coating colors-More than just viscosity , Chem. Eng. Technol. 20, 1997

27) Young T, Fu E., Associative behavior of cellulose thickeners and its implementation on coating structure and rheology, Coating Conference Proceedings Tappi press

28) Zeyringer E. and EichingerR., A new method to determine the water retention of coating colours and its impact on mottling of coated paperTappi Advanced Coating Symposium, October, 2010

Paper sent to revision: 07.09.2012.

Paper ready for publication: 05.12.2012. 